\title{
Assortative roosting in the two phonic types of Pipistrellus pipistrellus during the mating season
}

\author{
Kirsty J. Park ${ }^{1,2}$ John D. Altringham ${ }^{1}$ and Gareth Jones ${ }^{2}$ \\ ${ }^{1}$ Department of Biology, University of Leeds, Leeds LS2 9JT, U.K. \\ ${ }^{2}$ School of Biological Sciences, University of Bristol, Bristol BS8 1UG, U.K.
}

KJ Park fax: 01132332835 / 0117 9257374, email: K.J.Park@leeds.ac.uk / K.J.Park@bristol.ac.uk

JD Altringham fax: 0113 2332835, email: J.D.Altringham@leeds.ac.uk

G Jones fax: 0117 9257374, email: Gareth.Jones@bristol.ac.uk

Short title: Assortative roosting in Pipistrellus pipistrellus

Word count: 2951

Address for correspondence:

Kirsty J. Park, Department of Biology, University of Leeds, Leeds LS2 9JT

Telephone: 0113 2332859, fax: 0113 2332835, email: K.J.Park@leeds.ac.uk 


\section{SUMMARY}

The European pipistrelle, Pipistrellus pipistrellus consists of two phonic types that echolocate with frequencies of maximum energy (FMAXE) averaging $45 \mathrm{kHz}$ and 55 kHz. These two phonic types occur in sympatry over much of Britain. Between 1993 and 1995 mating groups of $P$. pipistrellus were located in bat boxes between August and October, the main mating period for these bats. Mating groups comprised a single male and up to three females. Broad-band, time-expanded recordings of search-phase echolocation calls were made from bats immediately after release. The average FMAXE of each bat was calculated: bats with an FMAXE $<49 \mathrm{kHz}$ were classed as $45 \mathrm{kHz}$ phonic types and bats with an FMAXE $>52 \mathrm{kHz}$ were classed as $55 \mathrm{kHz}$ phonic types. Sixteen $45 \mathrm{kHz}$ groups and ten $55 \mathrm{kHz}$ groups were located. No mating group ever contained more than one phonic type, although both types were known to be present at several of the study sites. Males emitted calls of higher frequency than females for both phonic types. The study suggests that the two phonic types are reproductively isolated and supports the hypothesis that $P$. pipistrellus should be considered as two cryptic sibling species.

\section{INTRODUCTION}

The pipistrelle bat Pipistrellus pipistrellus (Schreber 1774) is widespread throughout Europe (Stebbings 1988) and the most common bat in Britain (Harris et al 1995). P. pipistrellus has traditionally been considered to be one species, but Jones \& Parijs (1993) found that their search-phase echolocation calls fall into two discrete categories, 
with average maximum energy frequencies (FMAXE) at $45 \mathrm{kHz}$ and $55 \mathrm{kHz}$. Maternity roosts were found to contain only one of the phonic types and differences in flight morphology, roost size and general appearance were noted (Jones \& Parijs 1993). In continental Europe some areas appear to have only one of the phonic types, but in many areas both occur (Jones \& Parijs 1993). The phonic types are sympatric over much of Britain and it has been suggested that $P$. pipistrellus is two cryptic species (Jones \& Parijs 1993). Sequencing of the mitochondrial cytochrome $b$ gene indicates two distinct clades with a sequence divergence of approximately 12\% (Barratt et al. 1995). The two clades correspond unambiguously to the two phonic types (E.M. Barratt pers. com.).

P. pipistrellus employs a mating strategy of resource defence polygyny (Gerell \& Lundberg 1985). Males set up territories at a roosting site (including artificial 'bat boxes') at the beginning of summer and are joined by up to ten females after they leave the nursery colonies (Gerell \& Lundberg 1985; K.J.Park et al., in prep.). Males defend territories against other adult males and are thought to advertise the presence of their day roost to females by performing a song-flight display at night. The male flies along a fixed route within his territory emitting low-frequency vocalisations (Gerell-Lundberg \& Gerell 1994; Lundberg \& Gerell 1986). Song-flight calls of the two phonic types differ in frequency, and in the number of components (Barlow \& Jones, 1997).

If the two phonic types are separate species, reproductive isolation should occur. For the purpose of this study we have used the term mating group to describe roosting groups of reproductively active males and adult females in the same bat box during the mating season. We have looked at the composition of mating groups occupying artificial roost 
boxes at four localities in the U.K. to see if the criterion of reproductive isolation is fulfilled.

\section{METHODS}

The bat box sites are located mainly within the North Yorkshire Moors National Park (NYM), with additional sites in Dorset and Lancashire, on land managed by the Forestry Commission, and one site was in Surrey (see table 1). Between 1993 and 1995 mating groups were located by inspecting the bat boxes between August and October, the main mating period for these bats (Gerell \& Lundberg 1985). In the NYM bats have been ringed since 1985, and the phonic types of bats in some mating groups, documented before 1993 were identified retrospectively. Only mating groups in which the phonic types of all the bats were known have been analysed.

All bats were ringed (excluding three bats in the Surrey mating group), identified, sexed, aged (immature or adult) and reproductive status was assessed. Visible cartilaginous epiphyseal plates in finger bones of bats under a few months old allowed young bats to be distinguished from adults (Racey 1988). Males of most small vespertilionid bats achieve sexual maturity in their first full season of food abundance following birth but in some species females may become receptive to males in their first autumn (Racey 1988). In this study it was assumed that all young of the year in the post-parturition mating season were sexually immature. Immature males were never found in the mating groups. 
Bats were released from the hand several metres from the recording system. Recordings were made using a Pettersson D-980 ultrasound detector, in 10x time-expansion mode, and replayed to a Sony WM-D6C cassette recorder. One mating group (containing one male and two females) was recorded by K. E. Barlow using an Ultra Sound Advice S-25 detector to a Portable Ultrasound Signal Processor and replayed to a Sony WM-D6C cassette recorder. Jones \& Parijs (1993) investigated the two systems used here, and found there was no systematic variation in the FMAXE of the calls in relation to the equipment used.

Recordings were analysed using a Kay DSP 5500 digital Sona-graph. Only searchphase echolocation calls were used for analysis (Jones \& Parijs 1993). These calls have steep frequency-modulated (FM) sweeps with a constant-frequency (CF) tail. FMAXE was determined from power spectra with a resolution of $400 \mathrm{~Hz}$. FMAXE was always located in the CF tail of the call. The FMAXE reported here for each bat represents a mean of between two and 31 calls analysed per bat. Some bats were recorded more than once but only the FMAXE from the first occasion was used, and variation between recordings was minimal.

A 2 x 2 contingency table of male and female phonic type within a mating group was compiled. Bats $<49 \mathrm{kHz}$ were classified as $45 \mathrm{kHz}$ phonic types and bats $>52 \mathrm{kHz}$ were classified as $55 \mathrm{kHz}$ phonic types (Jones \& Parijs 1993). A single bat with an FMAXE averaging $50.11 \mathrm{kHz}$ was classed as indeterminate type and left out of the table (see discussion). This bat probably flew close to clutter (background substrate such as vegetation, echoes from which might interfere with echoes of interest to the bat 
(Neuweiler 1989)) and emitted broad-band calls with no evidence of a CF tail, resulting in considerable variability of FMAXE. To avoid pseudoreplication each male was entered into the contingency table only once with a randomly selected female he had been found with. The numbers of $45 \mathrm{kHz}$ phonic type males found with $45 \mathrm{kHz}$ phonic type females and the number of $45 \mathrm{kHz}$ phonic type males found with $55 \mathrm{kHz}$ phonic type females was entered. This was repeated for the $55 \mathrm{kHz}$ phonic type males. The Fisher Exact test was used to test the probability of finding the resulting distribution by chance.

The number of females in the mating groups of each phonic type was compared. One mating group was picked at random for males that had been found in the presence of adult females more than once. To determine whether $55 \mathrm{kHz}$ phonic type males roosted with $55 \mathrm{kHz}$ phonic type females assortatively by frequency within phonic type, the FMAXE of males was correlated with the FMAXE of a randomly selected female he had been found with. Insufficient data were available for a similar analysis to be performed on $45 \mathrm{kHz}$ bats. Analysis was carried out on MINITAB release 10 for Microsoft Windows (Ryan et al. 1985) and Sigmastat (Jandel Scientific).

\section{RESULTS}

A total of 26 mating groups were found and 48 individual bats recorded (15 males and 33 females). Of these, four males and six females were captured in mating groups between two and six times, all other bats being captured just once. No bat recorded more than once was found to have changed its phonic type. Fig. 1 shows the distribution 
of frequencies for the 46 bats for which exact FMAXE values were known (poor recordings of two bats prevented accurate determination of FMAXE). The distribution was clearly bimodal. The distribution of frequencies were approximately normal around $45.8( \pm 1.78) \mathrm{kHz}$ and $54.6( \pm 1.32) \mathrm{kHz}$ (means \pm standard deviations).

Fig 1 near here

None of the mating groups found contained bats of more than one phonic type. Of the 26 groups found, 16 were of the $45 \mathrm{kHz}$ phonic type and 10 of the $55 \mathrm{kHz}$ type. Using the contingency table described in methods, five $45 \mathrm{kHz}$ males have been found in mating groups with females that were always of the $45 \mathrm{kHz}$ phonic type and nine 55 $\mathrm{kHz}$ males have been found in mating groups with females that were always of the 55 kHz phonic type (Fisher Exact test, $p<0.001$ ).

Fig. 2 shows the FMAXE of each male against the FMAXE of each female he was found with. On some occasions the same male and female were found together more than once. The interval between finding the same male and female together varied from one week to two years. On all occasions where a male was found with the same female more than once within a season, the numbers of females, and the identity of some, in the mating group had changed. In both phonic types males had significantly higher frequency calls than females (mean FMAXE $45 \mathrm{kHz}$ phonic type males $=46.97 \pm 1.04$ $\mathrm{kHz}(n=5)$, females $=45.10 \pm 1.39 \mathrm{kHz}(n=16), W=82.5, p=0.026$, Mann-Whitney; mean FMAXE $55 \mathrm{kHz}$ phonic type males $=56.16 \pm 0.93 \mathrm{kHz}(n=7)$, females $=54.05 \pm$ $1.17 \mathrm{kHz}(n=17), W=138.5, p=0.001)$. Available data on forearm lengths of males 
and females of both phonic types indicate that males are significantly smaller than females (K.E. Barlow, unpubl. data).

Fig. 2 near here

All mating groups found contained one male and between one and three females. There was an average of $1.20( \pm 0.45, n=5)$ females in $45 \mathrm{kHz}$ phonic type mating groups and $1.78( \pm 0.67, n=9)$ in $55 \mathrm{kHz}$ phonic type mating groups (means \pm standard deviations). There was no difference in the size of mating group between the phonic types $(W=26.5$, n.s. $)$.

Within the $55 \mathrm{kHz}$ phonic type there was no correlation between the FMAXE of a male and a randomly selected female he had been found with (Pearson Product Moment Correlation , $r=0.278, n=7$, n.s.).

Table 1 shows the location and group composition of each mating group found with the average FMAXE of each bat. The two phonic types were sympatric at many of these sites. Eighteen mating groups were found across seven sites in the NYM. Both phonic types of $P$. pipistrellus have been found in bat boxes and recorded at three of these sites though the $45 \mathrm{kHz}$ phonic type predominates. On one occasion a male and female of the $45 \mathrm{kHz}$ phonic type were found copulating in a bat box in the NYM. Activity transects carried out over the study period at several locations in the NYM found both phonic types present feeding (KJP \& JDA, unpubl. data). Both phonic types have been found in the bat boxes in Lancashire though the three mating groups reported here are of the 55 
$\mathrm{kHz}$ phonic type. Only bats of the $55 \mathrm{kHz}$ phonic type were found in the boxes on the single visit to Dorset (four groups) and Surrey (one group) though maternity roosts of the $45 \mathrm{kHz}$ phonic type have been found within $4 \mathrm{~km}$ of the site in Surrey (K.E. Barlow, pers. com.).

Table 1 near here

DISCUSSION

This study shows that assortative roosting between the two phonic types of $P$. pipistrellus occurs during the mating season. Although it was not possible to confirm that all these were mating groups (a male and female were found copulating in a bat box on one occasion) evidence from other studies (e.g. Gerell \& Lundberg 1985) supports this assumption. This provides evidence of assortative mating between the two phonic types. The phonic types are sympatric across many of the sites where mating groups were located and this supports the proposal by Jones \& van Parijs (1993) that $P$. pipistrellus is two cryptic species.

Only $5 \%$ of bats recorded from maternity roosts by Jones \& Parijs (1993) produced echolocation calls with a FMAXE of between 49 - $52 \mathrm{kHz}$ and none of the bats whose social calls were recorded by Barlow \& Jones (1997) fell within this range. Only one of the 48 bats recorded in this study was found to be intermediate in FMAXE (table 1). The echolocation calls of this bat were not representative of typical search-phase calls as the recordings were made before the bat flew in open space. When flying in clutter, $P$. 
pipistrellus echolocation calls become broad-band, and lose their CF tail, which contains most of the signal's energy (Kalko \& Schnitzler 1993). The bat with an FMAXE of $50.11 \mathrm{kHz}$ is therefore not a bat of intermediate phonic type, but one that failed to emit search-phase calls of a suitable type for categorisation to phonic type. This bat was closer in frequency to a $45 \mathrm{kHz}$ phonic type than a $55 \mathrm{kHz}$ phonic type and genetic analysis has shown it to belong to the clade corresponding to the $45 \mathrm{kHz}$ phonic type (E.M. Barratt pers. com.). The bat was a male found with two $45 \mathrm{kHz}$ phonic type females.

$P$. pipistrellus mating groups contain one adult male and between one to ten females (Gerell \& Lundberg 1985; Gerell-Lundberg \& Gerell 1994; K.J.Park et al., in prep.). The bats from Gerell \& Lundberg's studies in Sweden are presumably of the $55 \mathrm{kHz}$ phonic type (Ahlén 1981; Jones \& Parijs 1993) and mating groups of comparable size are found in Britain. In this study there was no difference in the size of mating group between the two phonic types.

For both phonic types, males emitted echolocation calls of higher frequency than did females, and males are the smaller sex (K.E. Barlow, unpubl. data). P. pipistrellus therefore resembles Hipposideros speoris where males also emit calls of higher frequency than do females, though $H$. speoris does not show sexual size dimorphism (Jones et al. 1994). In other bat species, females emit higher frequency calls than males though there is no general rule that relates sexual dimorphism in call frequency to sexual size dimorphism (Jones 1995). 
The lack of a positive correlation between echolocation call frequency of males and females within the same mating group for the $55 \mathrm{kHz}$ phonic type suggests that assortative mating according to call frequency within phonic types does not occur, though the sample size here is too small to be able to draw any firm conclusions from this.

There is no experimental evidence as yet to support the assertion that the purpose of the males’ song-flight call is to attract females, though circumstantial evidence suggests that such a function is likely (Gerell \& Lundberg 1985; Gerell-Lundberg \& Gerell 1994). If this is the case, females should be able to distinguish between phonic type on the basis of the major differences between their songflight calls found by Barlow \& Jones (1997) and this would provide a mechanism for the assortative associations we have found.

\section{ACKNOWLEDGEMENTS}

Thanks to Charles Critchley and the Forest Enterprise rangers in the North York Moors for their help and for making fieldwork so enjoyable. Forest Enterprise (Pickering and York) provided financial and logistical support during the study. Thanks also to Eric Masters and Mark Warn (Forest Enterprise, Dorset), Kate Barlow, Adam Britton, Steve Bradley and Frank Greenaway for their help. KJP is funded by a Natural Environment Research Council studentship. GJ is funded by a Royal Society University Research Fellowship. 


\section{REFERENCES}

Ahlén, I. 1981 Identification of Scandinavian bats by their sounds Report 6, The Swedish University of Agricultural Sciences. Uppsala: Department of Wildlife Ecology.

Ahlén, I. 1990 Identification of bats in flight Stockholm: Swedish Society for Conservation of Nature.

Barlow, K.E. \& Jones, G. 1997 Differences in song-flight calls and social calls between two phonic types of the vespertilionid bat Pipistrellus pipistrellus. J. Zool.

Barratt, E.M., Bruford, M.W., Burland, T.M., Jones, G., Racey, P.A. \& Wayne, R.K. 1995 Characterization of mitochondrial DNA variability within the microchiropteran genus Pipistrellus: approaches and applications. Symp. zool. Soc. Lond. 67, 377-386.

Gerell, R. \& Lundberg, K. 1985 Social organisation in the bat Pipistrellus pipistrellus. Behav. Ecol. Sociobiol. 16, 177-184.

Gerell-Lundberg, K. \& Gerell, R. 1994 The mating behaviour of the pipistrelle and the Nathusius’ pipistrelle (Chiroptera) - a comparison. Folia Zool. 43, 315-324.

Harris, S., Morris, P., Wray, S. \& Yalden, D. 1995 A review of British Mammals: population estimates and conservation status of British Mammals other than cetaceans Peterborough: Joint Nature Conservation Committee.

Jones, G. 1995. Variation in bat echolocation: implications for resource partitioning and communication. Le Rhinolophe 11, 53-59. 
Jones, G. \& van Parijs, S. 1993 Bimodal echolocation in pipistrelle bats: are cryptic species present? Proc. R. Soc. Lond. B 251, 119-125.

Jones, G., Sripathi, K., Waters, D.A. \& Marimuthu, G. 1994 Individual variation in the echolocation calls of three sympatric indian hipposiderid bats, and an experimental attempt to jam bat echolocation. Folia Zool. 43, 347-362.

Kalko, E.K.V. \& Schnitzler, H.U. 1993 Plasticity in echolocation signals of European pipistrelle bats in search flight: implications for habitat use and prey detection. Behav. Ecol. Sociobiol. 33: 415-428.

Lundberg, K. \& Gerell, R. 1986 Territorial advertisement and mate attraction in the bat Pipistrellus pipistrellus. Ethology 71, 115-124.

Neuweiler, G. 1989 Foraging ecology and audition in echolocating bats. Trends Ecol. Evol. 4, 160-166.

Racey, P.A. 1988 Reproductive assessment in Bats. In Ecological and behavioural methods for the study of bats (ed. T.H. Kunz). pp. 31-45. Washington, D.C. \& London: Smithsonian Institution Press,.

Ryan, B.F., Joiner, B.I. \& Ryan, T.A. 1985 MINITAB handbook (2nd edition). Boston: PWS-Kent.

Stebbings, R.E. 1988 Conservation of European bats London: Christopher Helm. 


\section{FIGURE LEGENDS}

Figure 1. Distribution of FMAXE of echolocation calls of $46 P$. pipistrellus found in mating groups in the North York Moors National Park (25 bats), Lancashire (5 bats), Dorset (13 bats) and Surrey (3 bats). FMAXE is divided into $1 \mathrm{kHz}$ bands and the number of bats with a mean FMAXE within each band is shown. For example, the 45 kHz band contains bats with a mean FMAXE of between $44.50 \mathrm{kHz}$ and $45.49 \mathrm{kHz}$. Between 2 and 31 calls were recorded per bat and a mean value of FMAXE calculated. Poor recordings of two bats prevented accurate determination of FMAXE and these bats are not included.

Figure 2. The FMAXE of males plotted against the FMAXE of females they have been found with (open symbols $=45 \mathrm{kHz}$ phonic type $/$ closed symbols $=55 \mathrm{kHz}$ phonic type). Each male is represented by a different symbol. Numbers in parentheses indicate the number of times the male was found with the same female. Note that males have calls of a higher frequency than females. A line of equality has been included to illustrate this.

\section{TABLES}

Table 1. The location and group composition of the mating groups with the average FMAXE of each bat. ${ }^{1}$ est. denotes those bats for whom an accurate FMAXE was not obtained but were assigned to a phonic type from heterodyned recordings, where the CF tail of the sound made a 'slapping' sound (Ahlén 1990). In the NYM, individuals found 
in mating groups more than once have been assigned identities of M1 - M4 (male) and F1 - F6 (female).

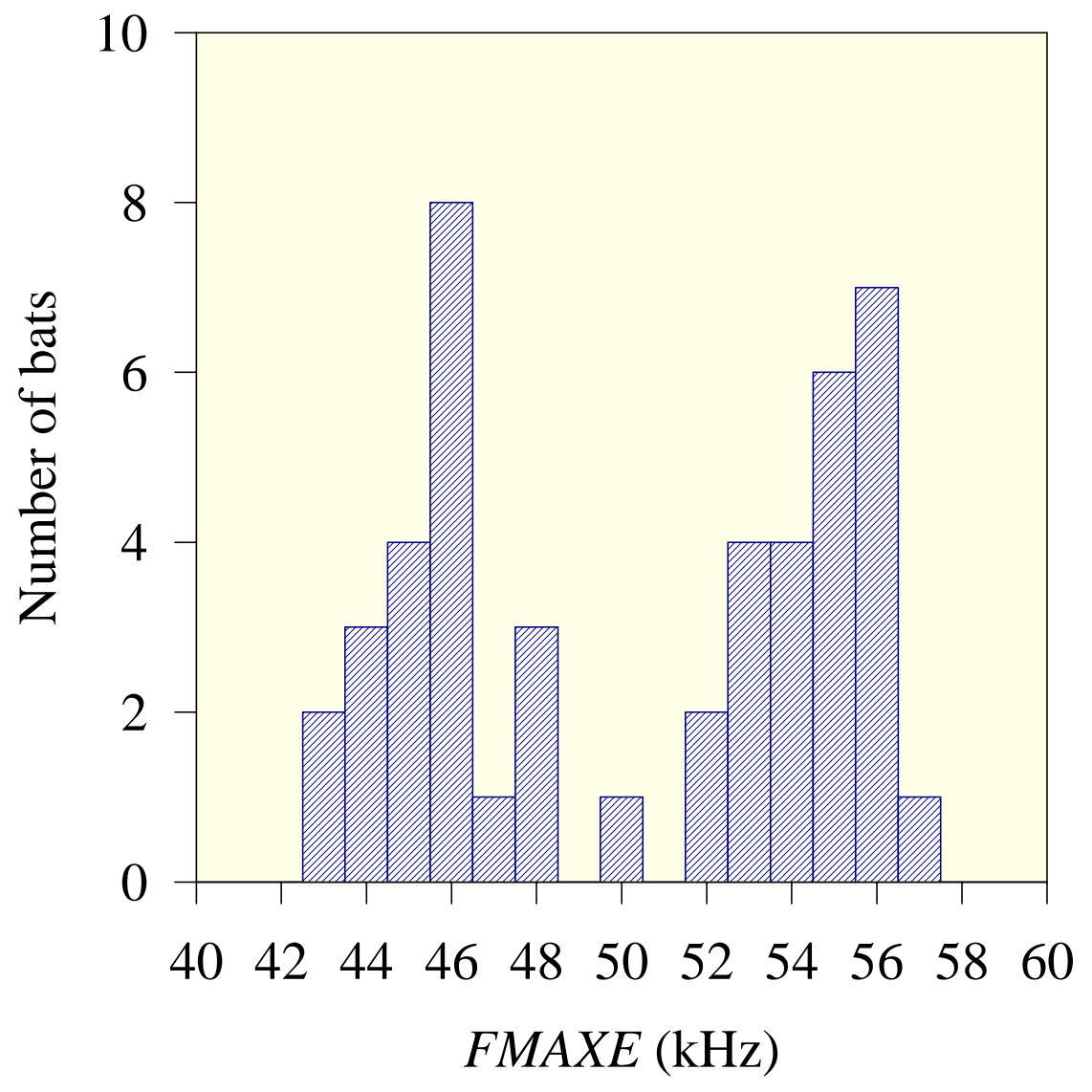

Figure 1 


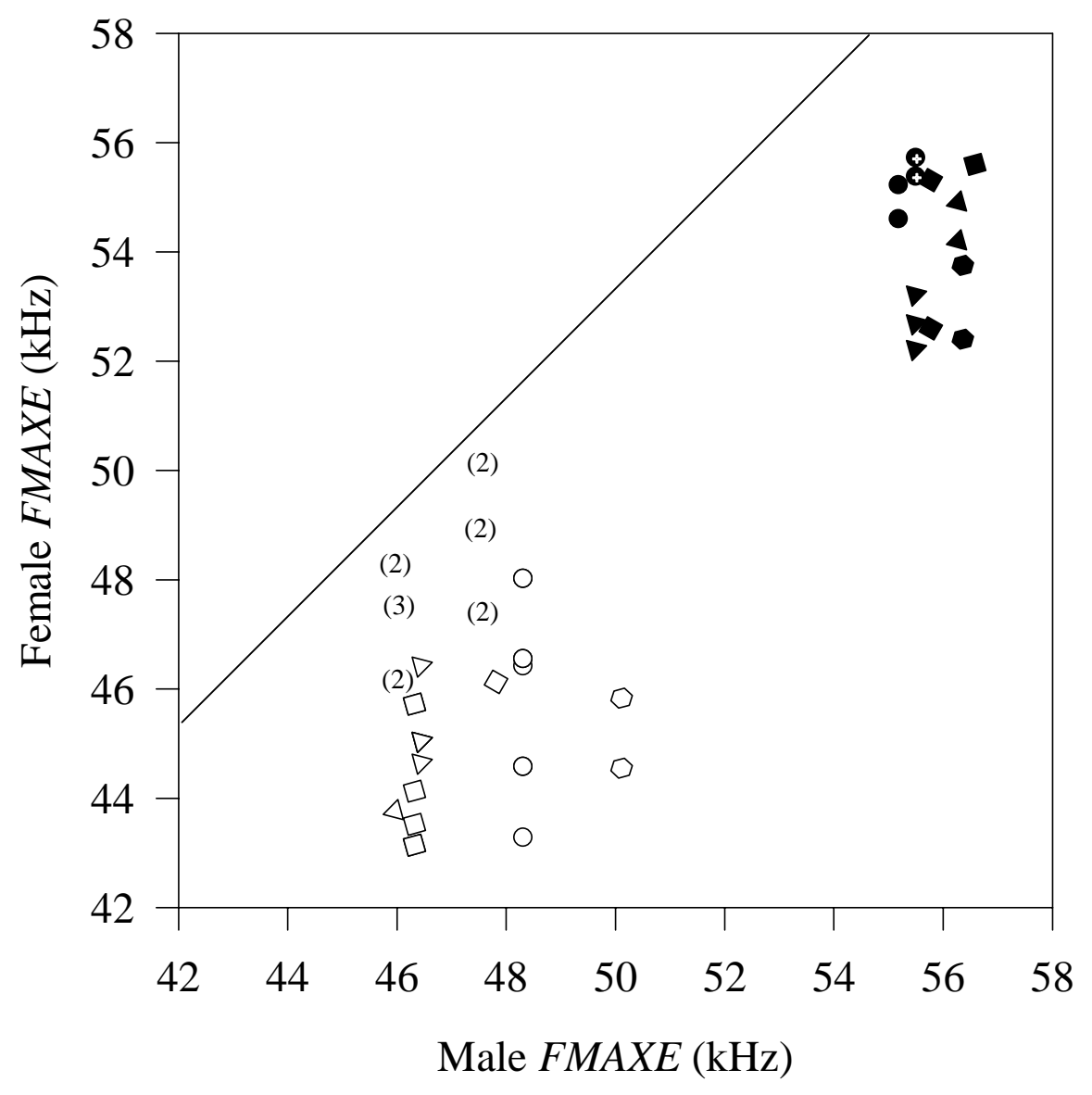

Figure 2 


\begin{tabular}{|c|c|c|c|c|c|c|c|c|c|}
\hline location (grid ref.) & date & sex & identity & FMAXE $(\mathrm{kHz})$ & location (grid ref.) & date & sex & identity & FMAXE (kHz) \\
\hline North York Moors: & \multirow{3}{*}{$14 / 09 / 88$} & & & & \multirow[t]{2}{*}{ SE896886 } & \multirow[t]{2}{*}{$16 / 09 / 93$} & $\mathrm{~m}$ & & $47.81 \pm 1.33(25)$ \\
\hline \multirow[t]{14}{*}{ SE774007 } & & $\mathrm{m}$ & M1 & $48.33 \pm 1.22(6)$ & & & $\mathrm{f}$ & & $46.13 \pm 1.29(15)$ \\
\hline & & $\mathrm{f}$ & & $43.26 \pm 0.71(7)$ & \multirow[t]{3}{*}{ SE930877 } & \multirow[t]{3}{*}{ 23/09/93 } & $\mathrm{m}$ & & $50.11 \pm 1.07(14)$ \\
\hline & \multirow[t]{2}{*}{ 19/10/89 } & $\mathrm{m}$ & M1 & $48.33 \pm 1.22(6)$ & & & $f$ & & $44.55 \pm 0.74(11)$ \\
\hline & & $\mathrm{f}$ & $\mathrm{F} 1$ & $44.56 \pm 0.46(5)$ & & & $f$ & & $45.83 \pm 1.22(14)$ \\
\hline & \multirow[t]{3}{*}{ 19/09/91 } & $\mathrm{m}$ & M1 & $48.33 \pm 1.22(6)$ & \multirow[t]{4}{*}{ SE856849 } & \multirow[t]{2}{*}{ 23/09/93 } & $\mathrm{m}$ & M4 & $56.27 \pm 0.72(15)$ \\
\hline & & $\mathrm{f}$ & $\mathrm{F} 1$ & $44.56 \pm 0.46(5)$ & & & $\mathrm{f}$ & & $54.19 \pm 2.04(28)$ \\
\hline & & $\mathrm{f}$ & $\mathrm{F} 2$ & $48.00 \pm 1.13(2)$ & & \multirow[t]{3}{*}{ 23/08/95 } & $\mathrm{m}$ & M4 & $56.27 \pm 0.72(15)$ \\
\hline & \multirow[t]{2}{*}{ 09/09/93 } & $\mathrm{m}$ & M1 & $48.33 \pm 1.22(6)$ & & & $\mathrm{f}$ & & $54.90 \pm 0.51(8)$ \\
\hline & & $\mathrm{f}$ & F2 & $48.00 \pm 1.13(2)$ & Lancashire: & & & & \\
\hline & \multirow[t]{3}{*}{ 30/09/93 } & $\mathrm{m}$ & M1 & $48.33 \pm 1.22(6)$ & SD510625 & \multirow[t]{2}{*}{$15 / 09 / 95$} & $\mathrm{~m}$ & & $56.58 \pm 1.33(9)$ \\
\hline & & $\mathrm{f}$ & & $46.40 \pm 0.40(5)$ & & & $\mathrm{f}$ & & $55.60 \pm 1.39(7)$ \\
\hline & & $\mathrm{f}$ & F3 & $46.53 \pm 1.51(6)$ & & \multirow[t]{3}{*}{ 15/09/95 } & $\mathrm{m}$ & & $53 \pm 1.00$ est. $^{1}$ \\
\hline & \multirow[t]{2}{*}{ 07/10/93 } & $\mathrm{m}$ & M1 & $48.33 \pm 1.22(6)$ & & & $\mathrm{f}$ & & $53.43 \pm 0.89(7)$ \\
\hline & & $\mathrm{f}$ & F3 & $46.53 \pm 1.51(6)$ & & & $\mathrm{f}$ & & $53.87 \pm 0.23$ \\
\hline \multirow[t]{9}{*}{ SE857866 } & \multirow[t]{4}{*}{$17 / 10 / 91$} & $\mathrm{~m}$ & M2 & $46.32 \pm 1.44(31)$ & & \multirow[t]{3}{*}{ 15/09/95 } & $\mathrm{m}$ & & $55 \pm 1.00$ est. $^{1}$ \\
\hline & & $\mathrm{f}$ & & $44.13 \pm 0.27(18)$ & & & $f$ & & $53.88 \pm 0.58(24)$ \\
\hline & & $\mathrm{f}$ & & $43.52 \pm 1.04(5)$ & Dorset: & & & & \\
\hline & & $f$ & $\mathrm{~F} 4$ & $43.14 \pm 0.59(7)$ & SY894933 & \multirow[t]{3}{*}{ 18/09/95 } & $\mathrm{m}$ & & $56.36 \pm 0.51(9)$ \\
\hline & \multirow[t]{3}{*}{ 16/09/93 } & $\mathrm{m}$ & M2 & $46.32 \pm 1.44(31)$ & & & $f$ & & $53.75 \pm 0.83(11)$ \\
\hline & & $\mathrm{f}$ & F4 & $43.14 \pm 0.59(7)$ & & & $\mathrm{f}$ & & $52.40 \pm 0.60(9)$ \\
\hline & & $\mathrm{f}$ & F5 & $45.72 \pm 1.31(24)$ & & \multirow[t]{3}{*}{ 18/09/95 } & $\mathrm{m}$ & & $55.48 \pm 0.60(13)$ \\
\hline & \multirow[t]{2}{*}{ 30/09/93 } & $\mathrm{m}$ & M2 & $46.32 \pm 1.44(31)$ & & & $\mathrm{f}$ & & $52.69 \pm 0.49(15)$ \\
\hline & & f & F5 & $45.72 \pm 1.31(24)$ & & & $\mathrm{f}$ & & $53.22 \pm 0.34(25)$ \\
\hline \multirow[t]{9}{*}{ SE914893 } & \multirow[t]{2}{*}{$12 / 08 / 93$} & $\mathrm{~m}$ & M3 & $46.43 \pm 0.97(13)$ & \multirow{4}{*}{ SY870932 } & & $\mathrm{f}$ & & $52.22 \pm 0.76(13)$ \\
\hline & & $f$ & F6 & $45.05 \pm 1.84(8)$ & & 18/09/95 & $\mathrm{m}$ & & $55.20 \pm 0.57(2)$ \\
\hline & 23/09/93 & $\mathrm{m}$ & M3 & $46.43 \pm 0.97(13)$ & & & $\mathrm{f}$ & & $54.58 \pm 0.57(9)$ \\
\hline & & $\mathrm{f}$ & F6 & $45.05 \pm 1.84(8)$ & & & $\mathrm{f}$ & & $55.20 \pm 0.75$ \\
\hline & & $\mathrm{f}$ & & $44.65 \pm 1.06(16)$ & SY924917 & 18/09/95 & $\mathrm{m}$ & & $55.77 \pm 0.63(24)$ \\
\hline & 30/09/93 & $\mathrm{m}$ & M3 & $46.43 \pm 0.97(13)$ & & & $f$ & & $52.60 \pm 0.57(2)$ \\
\hline & & $\mathrm{f}$ & F6 & $45.05 \pm 1.84(8)$ & & & $f$ & & $55.31 \pm 0.48(11)$ \\
\hline & $13 / 09 / 94$ & $\mathrm{~m}$ & M3 & $46.43 \pm 0.97(13)$ & Surrey: & & & & \\
\hline & & f & & $46.43 \pm 0.83(24)$ & SU895440 & 3/10/93 & $\mathrm{m}$ & & $55.52 \pm 0.33(5)$ \\
\hline SE840953 & 09/09/93 & $\mathrm{m}$ & & $45.96 \pm 0.83(11)$ & & & f & & $55.70 \pm 0.95(8)$ \\
\hline & & $f$ & & $43.76 \pm 0.66(10)$ & & & $\mathrm{f}$ & & $55.36 \pm 0.43(10)$ \\
\hline
\end{tabular}

Table 1 